\title{
IETS OVER DE BETEEKENIS \\ VAN DE ITHYPHALLISCHE BEELDEN BIJ DE VOLKEN VAN DEN INDISCHEN ARCHIPEL.
}

DOOŔ

Dr. G. A. WILKEN.

Het is van genoegzame bekendheid dat bij verscheidene volkeu van den Indischen Archipel, bij de vereering der voorouders, dikwijls gebruik gemaakt wordt van beelden, in welke beelden men zich de geesten der afgestorvenen, waar men zich met hen in betrekking wil stellen, aaṇwezig denkt ${ }^{1}$. Die beelden zijn in den regel van hout gemaakt en stellen een menschelijk figuur voor, sommigen in eene zittende, anderen in eene staande houding. Hetgeen echter vooral kenmerkend is, zijn de onevenredig groote genitaliën, waarmede sommige dier beelden voorzien zijn. Nergens treedt dit phallisme zoo sterk op den voorgrond als in den zoogenaamden rumsram of rumslam, den tempel gewijd aan de vereering der voorouders, van Dorei, aan de Geelvinksbaai op Nieuw-Guinea. Buitengewoon rijk is dit gebouw aan allerlei ontuchtige voorstellingen en ithyphallische beelden ${ }^{2}$. Men heeft hier aan Hindûschen invloed willen denken en in den rumsran een overblijfsel willen zien van den lingamdienst van het Çivaisme. Dit is - gelijk wij reeds elders uitvoerig hebben aangetoond ${ }^{3}-$ volkomen onnoodig. Onder de zegeningen, die men van de voor-

1 Zie hierover onze verhandeling: Het animisme bij de volken van den Indischen Archipel, blz. 164-172.

2 Zie over den rumsram onze, in de voorgaande noot genoemde, verhandeling, blz. 187-189, en de daar geciteerde bronnen.

3 O. c., blz. 189-192. 
ouders pleegt af te smeeken, behoort ook die van een talrijk kroost. Het kan dus geene verwondering baren, dat, als schenkers van leven en vruchtbaarheid, die voorouders wel eens voorgesteld worden door figuren, waaraan de organen, waarmede de voortplanting van het menschelijk geslacht zoo ten nauwste samenhangt, buitengewoon ontwikkeld en in het oog vallend afgebeeld zijn. Op die wijjze is zeker het phallisme in den voorouderendienst grootendeels te verklaren. Wij zeggen: grootendeels, want behalve de genoemde reden moet er nog eene andere zijn geweest, die de volken van den Indischen Archipel er toe gebracht heeft, om de beelden hunner afgestorvenen met den ontblooten phallus te voorzien. Het is ons voornemen dit in de volgende bladzijden kortelijk aan te toonen.

Ieder, die niet geheel vreemdeling is op het gebied der ethnologie, weet dat de phallus vaak aangewend wordt als eene amulet, een onheilwerend middel. Voornamelijk wordt dit gedaan tegen de werking van hetgeen men »het booze oog" noemt. Algemeen toch bestaat het geloof, niet alleen bij wilden doch ook bij meer beschaafde volken, dat er menschen zijn, die het vermogen bezitten, enkel door hunnen blik iemand een ongeluk te berokkenen, die anderen ziek kunnen maken, ja zelfs kunnen ombrengen, door hen eenvoudig aan te zien, die op deze wijze boomen kunnen doen verdorren, enz. ${ }^{4}$. Zeer juist heeft de bekende ethnoloog Richard Andree aangetoond, hoedanig dit geloof aan de werking van het booze oog zich moet hebben gevormd. „In der Redensart

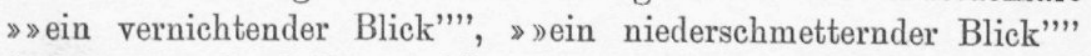
ist est ausgedrückt", zegt hịj onder anderen, »welche Macht und Kraft im menschlichen Auge liegt. Wie der imponirende Blick geistig hervorragender Menschen dem tiefer Stehenden das Gefühl seiner Nichtigkeit beibringt, ihn gleichsam moralisch schädigt, so kann auch leicht die Vorstellung Platz greifen, dass mit solchem Blicke eine Schädigung an Gesundheit, Eigenthum und Leben verknüpft sei. Im Fortgange dieses Glaubens werden dann besondere Personen mit dem so schädigenden Blicke ausgerüstet gedacht und diejenigen, welche sich dadurch bedroht wähnen,

4 Zie over het geloof ann het booze oog: Andree, Ethnographische Parallelen und Vergleiche, blz. 35-45; Ploss, Das Kind in Brauch und Sitte der Völker, dl. I, blz. $129-143$; Hodder M. Westropp, Primitive symbolism as illustrated in phallic worship, blz. $58-63$. 
suchen nach Schutz- und Abhilfmitteln gegenüber der zauberischen Einwirkung" 5 .

Onder de talrijke middelen, die aangewend worden om de werking van het booze oog te keeren, behoort ook, gelijk wij reeds opmerkten, de phallus. Als voorbeeld wijzen wij op de oude Romeinen. „Considéré comme un amulette, comme un fétiche portatif", zoo lezen wij onder anderen bij Dulaure, »le Phallus recevait le nom de Fascinum, et était d'un usage très fréquent chez les Romains qui ne connaissaient point de préservatif plus puissant contre les charmes, les malheurs et les regards funestes de l'Envie. C'était ordinairement une petite figure du Phallus en ronde bosse, de différentes matières; quelquefois c'était une médaille qui portait l'image du Phallus. On les pendait au cou des enfants et même ailleurs. On les plaçait sur la porte des maisons, des jardins, des édifices publics. Les empereurs, au rapport de Pline, en mettaient au devant de leurs chars de triomphe". Deze phallus-amuletten vertoonen eene groote verscheidenheid van vormen. „Les plus décents", gaat Dulaure voort, » offrent la figure d'une main fermée, et dont le pouce est placé entre les deux doigts qui le suivent: c'est cette figure que les antiquaires nomment main ithyphallique" ${ }^{6}$. Nog heden ten dage speelt in Italië het geloof aan het booze oog, mal occhio of occhio cattivo, in Napels, jettatura geheeten, eene voorname rol ${ }^{7}$, en worden daartegen dezelfde middelen angewend als vanouds. "Le fascinum", aldus weder Dulaure, west encore en usage dans la Pouille; et les habitants modernes de cette province, en imitant cette superstition des Anciens, ont aussi imité le motif qui les y déterminait. C'est pour écarter les maléfices et les regards funestes de l'envie qu'ils appendent, avec un ruban, aux épaules des enfants des fascinum

\footnotetext{
s Andree, Ethnographische Parallelen und Vergleiche, blz. 35. Zie ook: Tylor, Early history of mankind, blz. 137.

- Dulaure, Des divinités génératrices ou du culte du phallus chez les Anciens et les Modernes, blz. 145-146. Zie ook: Ploss, Das Kind, blz. 136; Westropp, Primitive symbolism, blz. $62-63$.

7 Kenmerkend is het zeker dat men in Rome aan Paus Pius IX bij zijn leven het booze oog toeschreef. An Italian countess was turned out of Rome, as she was scen making the sign against the Kvil Eye when the Pope was giving his blessing. An amusing story is also told of the late Pope, when saying prayers at the audience at the Vatican; on coming to the passage in the Lord's Prayer, "Lead us not into temptation", he looked over towards a very ugly old lady, upon which the lady boldly repeated aloud, "Deliver us from the Evil Eye", Libera nos a malo occhio (Westropp, Primitive symbolism, blz. 60).
} 
de corail, qui ont souvent la forme des mains ithyphalliques, et que les Italiens appellent fica" ${ }^{3}$. Heeft men geene amulet bij zich, dan voorkomt men de werking van het booze oog door met de rechterhand de fica te maken, far la fica gelijk dit heet. Als koning Ferdinand 1 van Napels zich in het openbaar vertoonde, placht hij van tijd tot tijd de hand in zijn zak te steken. Zij die hem kenden, wisten dat hij dan het teeken mano in fica maakte, de hand tot eene vuist balde en den duim tusschen den eersten en den tweeden vinger liet uitsteken, ten einde op die wijze den boozen blik te paralyseeren, dien iemand uit de menigte op hem zou kunnen werpen ${ }^{9}$. Doch het is niet alleen in Italië, dat wij het gebruik van den phallus of van nabootsingen van den phallus, als amulet tegen het booze oog, aantreffen. Het far la fica bij voorbeeld is evengoed bekend bij andere Romaansche volken, zooals bij de Portugeezen en de Spanjaarden, onder de benamingen dar huna figa en hazer la higa, terwijl het in Frankrijk ook voorkomt, waar het faire la figue heet ${ }^{10}$. Eindelijk, om nog

s Dulaure, Des divinités génératrices, blz. 255. - Daarnaast bezigt men andere middelen. Vooral draagt men tegen het booze oog amuletten, die den naam van Agnus Dei dragen en uit was en balsem vervaardigd zijn.

- Tylor, Early history of mankind, blz. 53; Andree, Ethnographische Parallelen und Vergleiche, blz. 45; Mallery, Sign language among North American Indians compared with that among other peoples, Annual report of the Bureau of Ethnology (Smithsonian Institution), 1879-80, blz. 300. In laatstgenoemde verhandeling wordt de mano in fica eene nabootsing van het pudenidum muliebre genoemd. Met Dulaure houden wij haar echter voor een ithyphallisch teeken.

$\left.{ }^{10}\right)$ Zie: Andree, Ethnographische Parallelen und Vergleiche, blz. 45; Ploss, Das Kind, dl. I, blz. 136-137. - Terloops willen wij hier er op wijzen hoe de hand nog op andere wijzen gebruikt wordt, om het booze oog te paralyseeren. Zoo vinden wij bij Andree eene Romeinsche hand-amulet afgebeeld, met uitgestoken duim en wijsvinger (Andree, O. c., blz. 45). Algemeener worden echter bij de oude Romeinen als middel tegen het booze oog aangewend bronzen handen met uitgestoken pink en wijsvinger. Nog heden ten dage worden in Italië dergelijke amuletten, uit koraal vervaardigd, den kinderen om den hals gehangen, en »legt man die Hand in diese Form und hält sie demjenigen entgegen, von dem man eine Verzauberung durch bösen Blick fürchtet". Men noemt dit »een hoorn maken" (Ploss, O. c., blz. 136; Tylor, Early history of mankind, blz. 53; Mallery, Sign language ete., blz. 248). In do derde plaats wordt nog de hand met de vijf vingers uitgespreid als afweermiddel tegen het booze oog aangewend. "Die Neugriechen und Albanesen halten gegen den gefürchteten Blick die Hand mit ausgespreitzten Fingern entgegen". (Ploss, O. c., blz. 139). Het gebruik van de hand op deze wijze is in de Mohammedaansche wereld zeer verbreid. „Wir treffen”, aldus Ploss (O. c., blz. 137), "die Hand mit den ausgestreckten fünf Fingern als Abwendungsmittel der Bezauberung nicht blos in Jerusalem in jüdischen, türkischen und arabischen Häusern, 
een voorbeeld hier aan te voeren, wijzen wij op de Indiërs, bij wie het teeken van den phallus, de lingam, senclosed in a small silver reliquary affixed to the breast or arm", gebezigd wordt »as an amulet or charm against the influence of the evil eye" 11 .

Het medegedeelde kan voldoende zijn om te doen zien, hoe algemeen de phallus gebruikt wordt als middel tegen kwade invloeden, in het bijzonder tegen het booze oog ${ }^{12}$. Ook in den

sondern auch in ganz Nord-Afrika: in Tunis, wo man zum Gegenzauber die nass. gemachte Hand in die $A$ sche des Herdes steckt und damit über Thüren und Fenster schlägt, in Algier, wo man an einem Korallenhalsband den Kindern goldene oder messingene Amulete in Form eines Händchens umgehängt, und in Marokko. Endlich begegnen wir der Hand als einem Schutz gegen den bösen Blick auch im Hofe der Alhambra". Dr. Goldziher te Budapest heeft in eene interessante verhandeling "Die Zahlen im mohammedanischen Volksglauben" (Ausland, 1884, blz. 328-330) in bijzonderheden dit gebruik van de hand als amulet in Palestina, Egypte en NoordAfrica aangetoond. Bekend is het dat onder de petroglyphen in America en Australië zich dikwijls afbeeldingen van handen bevinden (Andree, O. c., blz. 285, 289, 290, 299. Zie ook: Zeitschr. für Ethnol., dl. XVII, blz. 410 der »Verhandlungen"), en zoo zijn een paar jaren geleden op eenige eilandjes, in de golf van Muc-Cluer op Nieuw-Guinea, en evenzoo op de Kei-eilanden, onder andere figuren, ook afdrukken van handen aan de rotswanden gevonden (Tijdschr. v. Ind. T. L. en Vk., dl. XXIX, blz. 582-596; Zeitschrift für Ethnologie, dl. XVIl, blz. 407-409 der "Verhandlungen"). De vraag is nu: hoe hebben wij het gebruik van de hand p.ls amulet te verklaren? De gesloten hand met uitgestoken duim en wijsvinger, in de eerste plaats door ons genoemd, is klaarblijkelijk, evenals de mano in fica, eene nabootsing van den phallus, gelijk zij dan ook bij Andree als zoodanig wordt aangeduid. Op de beteekenis van het gebaar van den hoorn komen wij in noot 12 beneden terug. Hier willen wij alleen opmerken, dat het door sommigen beschouwd wordt als "to refer to the horns of animals slaughter in sacrifice" (Mallery, O. c., blz. 298), hetgeen ons echter onwaarschijnlijk voorkomt, afgescheiden daarvan dat het dan nog opgehelderd moet worden, waarom juist de hoorns van offerdieren als amuletten dienst kunnen doen. Wat eindelijk de hand met uitgespreide vingers betreft, de meening door sommigen uitgesproken (Goldziher, O. c., blz. 329) dat die als afweermiddel gebruikt wordt $"$ weil fünf als ominöse Zahl betrachtet wird", is onzes inziens minder juist. Integendeel, wij gelooven dat dit laatste juist een gevolg is van het eerste. Ook voor de beteekenis van dit gebaar verwijzen wij naar noot 12 beneden.

${ }^{11}$ Edward Sellon, On the phallic worship of India, Memoirs read before the Anthropological Society of London, janrg. 1863-64, blz. 328.

12 Meerdere voorbeelden kan men vinden in het aangehaalde werk van Dulaure (Zie de plaatsen angegeven in het register, blz. 370, i. v. amulettes). - Wij merken hier op, dat niet alleen de phallus, doch ook "zuweilen die weibliche Scham sich als Amulet gegen den bösen Blick gebraucht findet. Au die Stelle derselben treten auch gleichbedeutende Symbole, z. B. gewisse kleine Muscheln, die zorpivat hiessen, eben von dieser Aehnlichkeit. Auch die Araber brauchen die concha veneris, bei

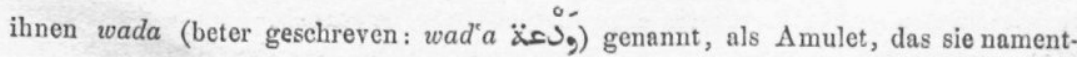


Indischen Archipel is dit het geval. Van de Amboneezen vinden wij vermeld, dat het bij hen niet zeldzaam is, dat, als twee personen met elkander twisten, de een den ander, bij wijze van uitdaging, zijn membrum virile toont ${ }^{13}$. In de Minahasa bootst men, gelijk wij tịjdens ons verblijf aldaar dikwijls hebben kunnen constateeren, in dergelijke gevallen den phallus na, door den

lich den Kindern gegen den bösen Blick um den Hals hängen" (Liebrecht, Zur Volkskunde, blz. 401). - Hoewel de vraag hoe men er toe gekomen is den lingam en de yoni, de voorstellingen van de mannelijke en de vrouwelijke genitaliën, als amulet te bezigen, buiten onze beschouwing ligt, wenschen wij er toch even bij stil te stran. Onzes inziens heeft men de verklaring van het rerschijnsel te zoeken in de vereering van de zon en de maan. De zon is eene goede godheid, die niet alleen zegen en viuchtbaarheid geeft, doch ook de machten der duisternis verjaagt en als zoodanig alle booze invloeden te keer gaat. Doch de zon is de hemelsche phallus, en hetgeen de hemelsche phallus doen kan, vermag, zij het op kleinere schaal, evenzeer de menschelijke. Hetzelf le geldt van de maan. Ook zij verjangt de duisternis en weert alle booze invloeden af. Doch de maan is eene vrouwelijke godheid, de gezellin van de zon, de hemelsche yoni. En wat nu de hemelsche yoni tot stand kan bren. gen, daartoe moet ook de menschelijke in staat zijn. Oorspronkelijk waren het dus de symbolen van zon en maan, die als amuletten dienst deden. Werkelijk vinden wij dit, wat de maan betreft, bevestigd. Immers de oude Romeinen gebruikten ook tegen het booze oog zoogenaamde lunulae, amuletten in den vorm van eene halvemaan, terwijl men nog heden ten dage in vele streken van Italië in bijna alle huizen koehoorns ophangt, ten einde elke betoovering te keeren, en de amuletten, die den kinderen om den hals gehangen worden, ook de gedante van koehoorns hebben (Ploss, Das Kind, dl. I, blz. 135 en 136; Andree, Ethnographisehe Parallelen und Vergleiche, blz. 45). Dat deze hoorns eene voorstelling van de halvemaan zijn, lijdt geen twijfel. Zoo zien wij immers ook Selene afgebeeld, zittende in een wagen door koeien voortgetrokken, die door hare hoorns symbolen van de halvemaanzzijn, en had deze godin in Elis een standbeeld met hoorns voorzien. En nu kan ons de zin ook duidelijk zijn van het gebaar van den hoorn, bedoeld hierboven in noot 10. Ne gesloten hand met uitgestoken wijsvinger en pink is slechts eene voorstelling van de halvemann, een symbool dus van de hemelsche, later van de menschelijke yoni. - Een enkel woord nog over de beteekenis van de hand met uitgespreide vingers in dezelfde noot genoemd. $W_{i j}$ meenen hierin slechts een symbool te zien van de rijzende zon. In de Amerikaansche petroglyphen vinden wij die hand dan ook werkelijk enkele malen in verbinding met de zon voorgesteld (Andree, O. c., blz. 285 en 289). Er is echter nog eene omstandigheid, die onze onderstelling eenigermate bevestigt. Evenals van andere symbolen van de rijzende zon, den ithyphallos der Grieken, den lingam der Indiërs (Zie: Schwartz, Der rothe Sonnenphallos der Urzeit, Zeitschr. für Ethnologie, dl. VI, blz. 170 en 179), is namelijk de kleur van de hand dikwijls rood. Zoo is dit het geval in Palestina en Algerië, en ook in America en Australië. Op Nieuw-Guinea en de Kei-eilanden hebben de handen, die aan de rotswanden zijn aangebracht, wel eene witte kleur, doch zijn toch de omtrekken daarvan rood gemaakt (Zie voor het voorgaande de in noot 10 opgegeven bronnen). Als symbool van de stralende zon, heeft dus ook de hand met uitgespreide vingers eene ithyphallische beteekenis.

13 Van Hoëvell, Ambon en meer bepaaldelijk de Oeliasers, blz. 139. 
middelsten vinger uit te steken en de andere vingers te krommen. De oorspronkelïke beteekenis van dit obscoen gebruik bij beide volken ligt voor de hand. Met het vertoonen van den phallus of van het teeken van den phallus moet men ook hier slechts ten doel hebben gehad, de nadeelige werking van den blik, door den een den ander tijdens den twist in toorn toegeworpen, te keeren.

Doch het is niet alleen tegen het booze oog, dat de phallus bij de volken van den Indischen Archipel wordt aangewend. Niet minder dient hij om booze geesten te verdrijven. Duidelïjk komt dit uit bij de bewoners van de Ceramlaoet-eilanden. Deze hebben het geloof, dat wind- en waterhoozen te voorschijn geroepen worden door booze geesten, om de menschen te benadeelen. Wanneer nu zulk een natuurverschïnsel zich voordoet, moet men den ontblooten phallus in de handen nemen en er naar wijzen, opdat de geest beschaamd wegtrekke ${ }^{14}$. Een dergelijk gebruik vindt men ook op de Philippijnen. Gelijk wij elders hebben aangetoond ${ }^{15}$, bestaat in den Indischen Archipel het geloof dat de tijdens hare zwangerschap gestorven, vooral echter de in het kraambed vóór de verlossing bezweken, vrouwen, niet in het graf blijven, doch als spoken in de wereld der levenden terugkeeren. Deze spoken dragen in het Maleisch den naam van pontijanaq of puntijanaq, welke naam met eenige klankwijziging bï de voornaamste stammen van den Archipel voorkomt. De pontijanaq's, die als vóór de bevalling overleden vrouwen de moedervreugde niet hebben mogen smaken, gunnen die ook aan hare zusteren niet, en zijn er dus vooral op uit miskramen te veroorzaken of in het algemeen zwangeren leed te doen. Ook bij de Tagala's en Bisaya's van de Philippijnen nu treft men dit geloof aan den pontijanaq, of, gelijk de benaming hier luidt, patianak, aan. De patianak's worden ook hier geacht het bijzonder op de kraamvrouwen gemunt te hebben. Om deze spoken te verdrijven worden allerlei middelen te bat genomen. „Als bestes Mittel', aldus lezen wij nu, »gilt folgendes: Da der Patianak vor allem Nackten eine grosse Scheu besitzt, so besteigt der Ehegatte, bei dessen Weib die Geburtswehen eintreten, vollständig nackt oder nur mit einem Schurze bekleidet, das Dach seines Hauses, er ist mit

14 Riedel, De sluik- en kroesharige rassen tusschen Selebes en Papua, blz. 187.

is Zie onze verhandeling: Het animisme bij de volken van den Indischen Archipel, blz. $197-204$. 
Schwert, Schild und Lanze bewaffnet; ähnlich ausgerüstete Freunde stellen sich um und unter die (auf Pfählen ruhende) Hütte; alle beginnen mit rasender Wuth in die Luft zu hauen und zu stechen, dadurch werden nach ihrem Glauben die Unholde in Angst versetzt und ziehen sich wieder zurück". Uit hetgeen wij nu verder medegedeeld vinden, blijkt duidelijk dat het doel, waarom de mannen zich van hunne kleederen ontdoen, bepaaldelijk is om den patianak de genitalia te vertoonen, en hem daarmede schrik aan te jagen. „Die Tagalen", aldus heet het toch, sschreiben es dem Patianak zu, wenn sie von ihrem Wege abkommen und sich verirren; um den rechten Weg wieder zu finden, ziehen sie sich nackt aus und entblössen die Genitalien, wodurch der Patianak erschreckt wird und nicht mehr im Stande ist sie irrezuleiten" ${ }^{16}$. Dit gebruik om den pontijanaq te verdrijven door hem den phallus te vertoonen, treft men nog aan op het eiland Lombok, volgens eene door ons, door tusschenkomst van Dr. Brandes, van Dr. Van der Tuuk ontvangen mededeeling ${ }^{17}$.

$\mathrm{Na}$ het hiervoren aangevoerde, behoeft de verklaring van het phallisme in den voorouderendienst niet ver meer gezocht te worden. Waar het geloof bestaat dat de ontbloote phallus een middel is om booze invloeden te keeren, daar is het niet meer dan natuurlijk dat aan de figuren, die van de afgestorvenen worden gemaakt, dat orgaan buitengewoon ontwikkeld en in het oog vallend afgebeeld wordt. Immers de zielen van de afgestorvenen zijn in de eerste plaats beschermgeesten. Het is dan ook, althans in den rumsram van Dorei, vooral bij de beelden welke, blïkens het zwaard en het schild waarmede zij voorzien zijn, de voorouders meer bepaaldelijk in die hoedanigheid van beschermgeesten voorstellen, dat het ithyphallisme gevonden wordt ${ }^{18}$.

16 Blumentritt, Der Ahnencultus und die religiösen Anschauungen der Malaien des Philippinen-Archipels, blz. 30-31.

17 Bij de andere volken van den Archipel vindt men juist omgekeerd het geloof, dat de pontijanaq's er vooral op uit zijn de mannen van hunne genitalia te berooven (Zie onze verhandeling over het animisme, t. a. p.).

1s Zie bij voorbeeld de af beelding voorkomende in het werk : Nieuw-Guinea, ethnographisch en natuurkundig onderzocht en beschreven, Pl. WW. Gelijk wij aan het slot van noot 12 gezien hebben, heeft de geopende hand eene ithyphallische beteekenis. Hieruit laat het zich waarschijnlijk verklaren, dat men op Roti de afgestorvenen, in hunne hoedanigheid van beschermgeesten, in plaats van door ithyphallische beelden, door de zoogenaamde maiks voorstelt, nitgesneden lontarbladen bijna in den vorm van eene menschenhand (Zie onze verhandeling over het animisme, blz. 169). 
Alvorens te eindigen, willen wij volledigheidshalve hier nog opmerken, dat het niet alleen de beelden van de zielen der afgestorvenen zijn, welke op die wijze met den ontblooten phallus zijn voorzien. Ook andere wezens, welke als beschermgeesten dienst doen, worden door dergelijke figuren voorgesteld. Wij wijzen hier slechts op het beeld, dat voorheen bij den stam der Ulisiwa's, op de Ambonsche eilanden, vereerd werd onder den naam van ButuUlisiwa, dat is: de phallus der Ulisiwa's. Gelijk de naam het reeds aanduidt, wordt het gekenmerkt door een onevenredig groot geslachtsdeel. "Deze snoode afgod", aldus lezen wij bij Valentijn, "wierd niet alleen toen zy nog Heidenen waren, van hen gediend, maar in 't jaar 1656 heeft zeker korporaal, die op Way lag, ten tyde van de Heer Arnold de Vlaming zulk eenen afgod aldaar, zeven voeten groot, met een mannelyk teellid, wel twee spannen lang, wreed van gezigt, en spits van knevels, ontdekt, zonder dat men oit te voren daar af gehoord had, alzoo zy hem in een ontoegankelyken schuilhoek verborgen hadden" 19. Welke godheid door dit beeld voorgesteld wordt, blijkt niet. Alleen deelt Valentijn mede, dat de Amboneezen den Butu-Ulisiwa niet alleen dienden "om daar door, zoo zy voorgaven, te bewerken, dat hunne vrouwen vrugtbaar mogten zijn” 20 , doch ook dat zij hem vereerden "als den God, die hen voorspoed op zee, en overwinning tegen de vyanden geven moest", waarom zij dan ook "Zoo een afgodsbeeld op de coracora (vaartuigen) in oude tyden plagten gesneden en verborgen te hebben" 21. Ook hier is dus de ontbloote phallus een afweermiddel.

LeIden, Juni 1886.

\footnotetext{
19 Valentijn, dl. III, 1, blz. 4-5.

${ }^{20}$ Valentijn, dl. III, 1, blz. 57.

21 Valentijn, dl. III, 1, blz. 5 .
} 